\title{
Toll-like receptor 4 agonist-based nanoparticles orchestrate protection against sepsis
}

\author{
Yongxiang Zhao ${ }^{1}$, Xinjing Lv ${ }^{1}$, Jie Huang ${ }^{1}$, Huiting Zhou ${ }^{1}$, Hairong Wang ${ }^{1}$, Jian Wang ${ }^{1, *}$, and \\ $\mathrm{He} \mathrm{Zhao}^{1, *}$ (D) \\ ${ }^{1}$ Children's Hospital of Soochow University, Pediatric Research Institute of Soochow University, Suzhou 215123, Jiangsu, China
}

Received: 17 August 2021

Accepted: 14 October 2021

Published online:

1 January 2022

(C) The Author(s) 2021

\begin{abstract}
Sepsis, a life-threatening organ dysfunction induced by severe infection and uncontrolled host immune response, threatens the health of people all over the world. Herein, a type of nanoparticle formulation with simple components is synthesized by encapsulating monophosphoryl lipid A (MPLA), a TLR4 agonist, with poly(lactic-co-glycolic acid) (PLGA) nanoparticle. The obtained nanoparticles (MPLA@PLGA) could provide Escherichia coli (E. coli)-induced sepsis protection by regulating the immune system after sepsis challenge, including promoting the levels of various cytokines, boosting the percentage of natural killer cells and accelerating bacterial clearance. Notably, the survival mice pretreated with these nanoparticles could resist repeated E. coli-induced sepsis. Our work therefore provides the great promise of MPLA@PLGA nanoparticles as a simple yet effective nano-drug for prevention and protection against E. coli-induced sepsis.
\end{abstract}

\section{Introduction}

The increasing misuse of antibiotics has led to an increasing rate of drug resistance in various infectious diseases, such as pneumonia and urinary tract infection [1,2]. As one of the most common causes of death in hospitalized patients, sepsis, defined as lifethreatening organ dysfunction induced by severe infection and uncontrolled host immune response, threatens the health of people all over the world. It has been reported that more than 19 million people suffer from sepsis each year, as well as a death rate of more than $40 \%$ [3, 4]. Furthermore, about 3 million surviving patients have organ dysfunction, such as infective cardiomyopathy, or cognitive impairment [5-8]. It was also found in clinical studies that the pre-infection immune status of clinical patients would directly determine the prognosis of infected patients [9]. And immunomodulators can regulate the in vivo release of cytokines, improve the immune function of sepsis patients, effectively maintain the

Handling Editor: Christopher Blanford.

Yongxiang Zhao and Xinjing Lv contributed equally to this work.

Address correspondence to E-mail: wj196312@vip.163.com; zh2021@suda.edu.cn 
in vivo normal immune homeostasis in sepsis patients, reduce injuries of important organs and decrease the mortality of sepsis [10-12]. Therefore, it is important to use immunomodulators for preventing and treatment of sepsis induced by severe infection, which may provide new treatment options for sepsis patients.

The interactions between pathogen-associated molecular patterns (PAMPs), defined as highly conserved molecular structure in pathogenic microorganism, and pattern recognition receptors (PRRs) play an important role in the prevention and treatment of sepsis, including the recognition of infectious pathogens, the initiation of host inflammatory response and the activation of host immune defense [13-15]. Toll-like receptor (TLR) 4 activator, a typical PAMP with powerful biological functions, can regulate host inflammation, recruit granulocytes and macrophages to the infected sites and effectively promote pathogen clearance [16]. Furthermore, the insufficient activation of TLR4 signaling pathway in the host can promote the occurrence of infection and aggravate the progress of infection [1, 17, 18]. And it was found that the anti-infective capability was enhanced in clinical patients pre-treated with TLR4related immunoregulators [19-21]. Therefore, it is important for the prevention and treatment of various infections by using TLR4 immunoregulators, especially sepsis.

Monophosphoryl lipid A (MPLA), a TLR4 agonist used as vaccine adjuvant in clinic, can enhance the in vivo bactericidal efficacy of granulocytes and macrophages without the release of cytotoxic products [22-24]. However, MPLA is a hydrophobic molecule with poor water solubility. Herein, based on the above findings, MPLA loaded into poly(lacticco-glycolic acid) (PLGA) nanoparticles, a polymeric carrier that has been widely used as drug delivery and approved by FDA for clinical use, is developed [25]. We hypothesized that these nanoparticles (MPLA@PLGA) could continuously release MPLA post-intradermal injection to provoke immunological effect for Escherichia coli (E. coli)-induced sepsis protection by stimulating intradermal immune cells and host immune system (Fig. 1a). The rate of survivors in the MPLA@PLGA-treated group was significantly increased. Excitingly, the survival mice preinjected with MPLA@PLGA could resist to the repeated E. coli-induced sepsis challenge. Therefore, this nanoparticle could be used as a simple yet effective preventive nano-drug for bacteria-induced sepsis protection.

\section{Materials and methods}

\section{Materials}

Raw 264.7 cells, a kind of murine cell line, were cultured in Dulbecco's modified Eagle medium (DMEM) containing $10 \%$ fetal bovine serum (FBS), $100 \mathrm{IU} / \mathrm{mL}$ of penicillin and $100 \mu \mathrm{g} / \mathrm{mL}$ of streptomycin in a humidified atmosphere incubator with $5 \% \mathrm{CO}_{2}$ at $37^{\circ} \mathrm{C}$. Dimethyl sulfoxide (DMSO) and dichloromethane $\left(\mathrm{CH}_{2} \mathrm{Cl}_{2}\right)$ were purchased from Chinasun Specialty Products Co., Ltd. The antibodies for flow cytometry assay were obtained from BioLegend. Limulus amebocyte lysate (LAL) endotoxin assay kit was obtained from GeneScript. Other unmentioned chemicals were purchased from Sigma-Aldrich.

All the C57BL/ 6 mice (6-8 weeks, female) in the experiments were fed under standard laboratory conditions (ventilated room, $25 \pm 1{ }^{\circ} \mathrm{C}, 60 \pm 5 \%$ humidity, 12-h light/dark cycle) and had free access to standard water and food. All procedures were conducted in accordance with the "Guiding Principles in the Care and Use of Animals" (China) and were approved by Soochow University Laboratory Animal Center (approval number: SYXK(Su) 2017-0043).

\section{Fabrication of MPLA@PLGA nanoparticle}

MPLA@PLGA nanoparticle was produced by using a previously reported $\mathrm{O} / \mathrm{W}$ single-emulsion method [27]. Briefly, monophosphoryl lipid A (MPLA) was dissolved in DMSO solution. Ten milligrams of PLGA was added into $0.4 \mathrm{~mL} \mathrm{CH}_{2} \mathrm{Cl}_{2}$ solution and then added to PVA solution $(0.8 \mathrm{~mL}, 50 \mathrm{mg} / \mathrm{mL})$. MPLA solution $(1 \mathrm{mg} / \mathrm{mL}, 20 \mu \mathrm{L})$ was mixed with the above solution and homogenized by ultrasonic at $200 \mathrm{w}$ for $30 \mathrm{~min}$ after adding $2.2 \mathrm{~mL}$ deionized water. Then, the emulsion was added into PVA solution $(50 \mathrm{mg} / \mathrm{mL}, 1 \mathrm{~mL})$ and stirred overnight at room temperature. The MPLA@PLGA nanoparticles were obtained by centrifuging $(30,000 \mathrm{rpm}, 15 \mathrm{~min})$ and washed by deionized water.

Fluorescent dye DID encapsulated into PLGA nanoparticles (DID@PLGA) was synthesized by the same method by using DID instead of MPLA. 
(a)

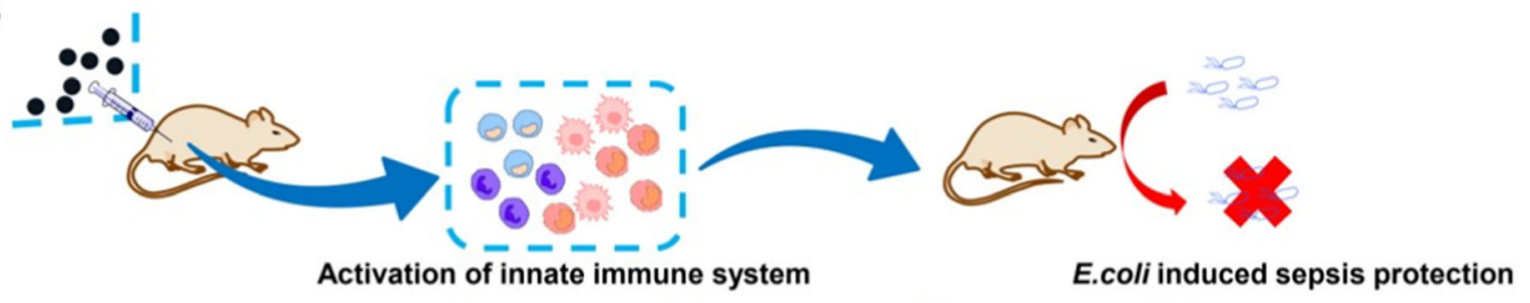

MPLA@PLGA nanoparticles

(b)

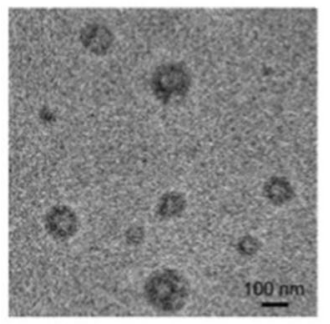

(c)

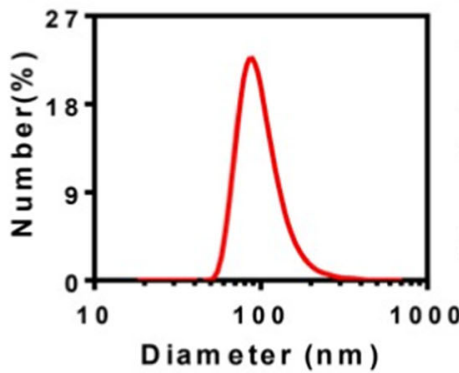

(d)

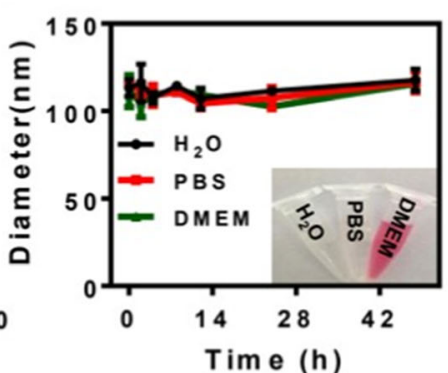

(e)

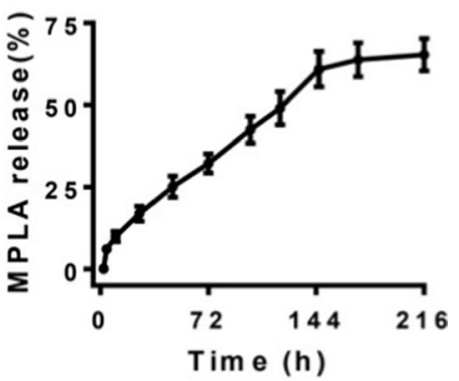

Figure 1 Synthesis and characterization of MPLA@PLGA nanoparticles. a The schematic illustration of the synthesis and function of MPLA@PLGA nanoparticles. b A TEM image of MPLA@PLGA nanoparticles. c The size distribution of MPLA@PLGA nanoparticles. d The diameter profiles of

\section{Characterization and drug release of MPLA@PLGA}

The diameter and stability in various solutions of MPLA@PLGA were determined by dynamic light scattering (Zetasizer Nano-ZS). The transmission electron microscopy (TEM) image of the nanoparticles was obtained by JEM-1230. The release and encapsulation efficiency of MPLA encapsulated into the nanoparticles were determined by the LAL endotoxin assay kit.

\section{In vitro bacterial uptake}

E. coli was cultured at $37^{\circ} \mathrm{C}$ in Trypticase soy broth, harvested at the mid-logarithmic growth phase, washed three times and resuspended in PBS for the in vitro experiments. The collected E. coli, heat-killed for $30 \mathrm{~min}$ at $95{ }^{\circ} \mathrm{C}$, was labeled by Cy5.5 (E. colicy5.5). The RAW 264.7 cells, cultured in 24-pore plate, were then stimulated with MPLA@PLGA $(0.2 \mu \mathrm{g} / \mathrm{mL}$ MPLA) for $6 \mathrm{~h}$. The stimulated raw 264.7 cells were incubated with E. coli-cy5.5 at $37^{\circ} \mathrm{C}$ for $30 \mathrm{~min}$ (the ratio of cell $/$ bacteria $=1 / 20)$. The $E$. coli uptake was analyzed by flow cytometry and confocal fluorescence microscope (OLYMPUS).
MPLA@PLGA nanoparticles in water, PBS or DMEM at different time points. e The MPLA release of MPLA@PLGA nanoparticles in water at various time points. Data are presented as mean \pm the standard errors of the mean (SEM).

\section{In vivo subcutaneous fluorescence imaging}

DID@PLGA nanoparticles were intradermally injected into the skin of healthy mice. The DID signal in the back skin was detected at different time points by PE Lumina III.

In vivo $E$. coli challenge and analysis of immunocyte and cytokine

C57BL/ 6 mice (6-8 weeks, female) were randomly distributed in the PBS or MPLA@PLGA group. All the mice were challenged by E. coli $\left(5 \times 10^{6} \mathrm{CFU}\right)$ at $24 \mathrm{~h}$ after intradermal injection of MPLA@PLGA (0.1 mg/kg MPLA). Survival was monitored for at least 14 days.

At $6 \mathrm{~h}$ after E. coli challenge, the main organs from the mice, killed by cervical dislocation, were acquired and determined for E. coli counts.

The expression levels of the markers in different immune cells in blood and peritoneal lavage fluids were measured by a flow cytometer at $6 \mathrm{~h}$ post-sepsis challenge. The concentration of cytokines was analyzed by ELISA. 


\section{Statistical analysis}

All results were expressed as means \pm SEM. Student's t-test was performed when two groups were compared. Statistical differences in survival were determined by the log-rank test. The statistical analyses were performed with GraphPad Prism and Origin. ${ }^{*} p<0.05,{ }^{* *} p<0.01$ and ${ }^{* * *} p<0.001$.

\section{Results and discussion}

PLGA is a kind of clinically approved biomedical polymer and widely used as a drug carrier for drug delivery [26]. MPLA, a kind of TLR4 agonist, was encapsulated into PLGA nanoparticles (MPLA@PLGA) through a previously reported method [27]. As revealed by transmission electron microscopy (TEM) image, it was shown that the synthesized MPLA@PLGA had a uniform spherical structure (Fig. 1b). The average diameter of MPLA@PLGA nanoparticles, exhibited by dynamic light scattering data, was about $110 \mathrm{~nm}$ (Fig. 1c). The encapsulation efficiency of MPLA loaded into PLGA nanoparticles, measured by the LAL endotoxin assay kit, was about $49.43 \%$. Furthermore, it was shown that the MPLA@PLGA nanoparticles could be stable in deionized water, phosphate buffer saline (PBS) solution and DMEM cell culture medium (Fig. 1d), indicating the good stability in various solutions. The release profile of MPLA was then studied by using the LAL endotoxin assay kit to measure the released MPLA (Fig. 1e). It was found that the slow release of MPLA encapsulated with PLGA nanoparticles could be observed.

Next, DID fluorescent dye loaded into PLGA nanoparticles (DID@PLGA), the surrogates for MPLA@PLGA, was used to mimic and evaluate the in vivo retention of the MPLA (Fig. $2 b$ and $c$ ), which was intradermally injected into the healthy C57/BL6 mice. As shown by fluorescence imaging, the DID@PLGA nanoparticles showed prolonged retention in vivo.

Furthermore, the anti-infective effect enhanced by the MPLA@PLGA nanoparticles was detailed studied in vivo (Fig. 2a). Firstly, the PBS-treated or MPLA@PLGA-treated mice were given intradermal injection of PBS or MPLA@PLGA $(0.1 \mathrm{mg} / \mathrm{kg}$ MPLA), respectively. At different time points $(6 \mathrm{~h}$, $24 \mathrm{~h}$ and $48 \mathrm{~h}$ ) post-intradermal injection, all the mice
Figure 2 In vivo protective effect against $E$. coli-induced sepsis induced by the MPLA@PLGA nanoparticles. a Schematic illustration to exhibit the protection of the MPLA@PLGA nanoparticles after different time points in $E$. coli-induced sepsis. $\mathbf{b}$ and $\mathbf{c}$ In vivo fluorescence imaging photographs $\mathbf{b}$ and quantification (c) of release profiles of DID encapsulated with PLGA nanoparticles (DID@PLGA). d and e Survival rate (d) and individual body weights (e) of the mice challenged by $E$. coliinduced sepsis ( $n=5$ per group) at different time points after MPLA@PLGA nanoparticles intradermal injection. ( $f$ and g) Survival rate (f) and individual body weights (g) of the mice $24 \mathrm{~h}$ after different treatments challenged by E. coli-induced sepsis ( $n=12$ per group). S, survival rate. (h and i) Representative images (h) and the statistic data (i) of E. coli colonization in the major organs of the mice at $6 \mathrm{~h}$ after sepsis challenge $(n=3$ per group). Black and red points mean PBS-treated and MPLA@PLGA-treated group, respectively. (j) h and e staining images of the major organs of the mice at $16 \mathrm{~h}$ after sepsis challenge. Data are presented as means \pm SEM. Survival curves were compared by log-rank test. Statistical significance was calculated by Student's $t$-test.

were acquired by lethal intraperitoneal injection $\left(200 \mu \mathrm{L}, 5 \times 10^{6} \mathrm{CFU}, E\right.$. coli). It is exhibited in Fig. $2 \mathrm{~d}$ that all the mice treated by PBS died within $25 \mathrm{~h}$, while the mice treated by MPLA@PLGA nanoparticles could achieve $60 \%$ for 6 -h treatment, $80 \%$ for $24-\mathrm{h}$ treatment and 48 -h treatment, respectively. The survival data demonstrated that sepsis protection induced by the MPLA@PLGA nanoparticles could be enhanced by the in vivo increased release of MPLA. The body weight of the living mice turned to the healthy weight within 5 days after sepsis challenge (Fig. 2e).

Based on the in vivo efficiency of sepsis protection, we chose to evaluate and analyze the in vivo antibacterial effect of MPLA@PLGA nanoparticles about $24 \mathrm{~h}$ post-intradermal injection. Firstly, the sample size in MPLA@PLGA-treated group was expanded to repeat the sepsis protection of MPLA@PLGA nanoparticles. It was found that the mice treated with MPLA@PLGA nanoparticles could achieve $\sim 83.33 \%$ survival, while the mice in PBS group were all death (Fig. 2f). The survival result proved that the activation of TLR4 signaling pathway could promote effective sepsis protection. Notably, the body weight of the survival mice increased to preinfected level about 5 days after E. coli-induced sepsis challenge (Fig. 2g). Furthermore, such sepsis protection induced by MPLA@PLGA nanoparticles was 
(a)

(b)

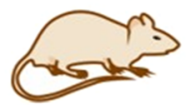

Healthy mouse

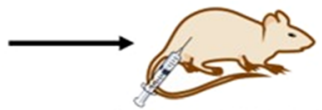

MPLA@PLGA (i.d.)

Time (h) 4

옴 (h) 4

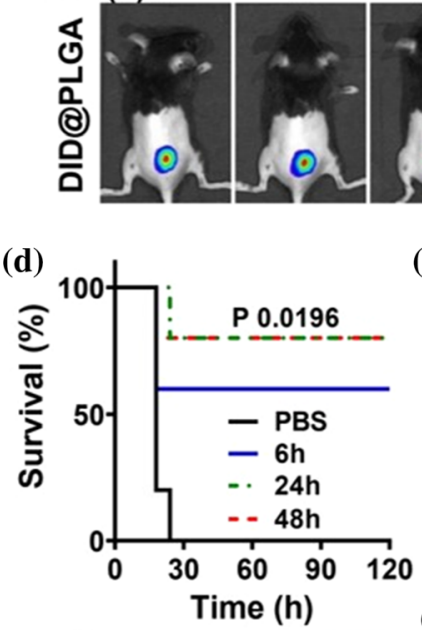

(e)

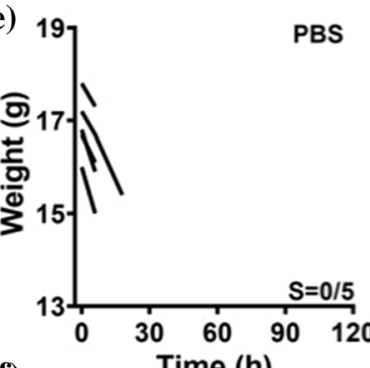

(f)

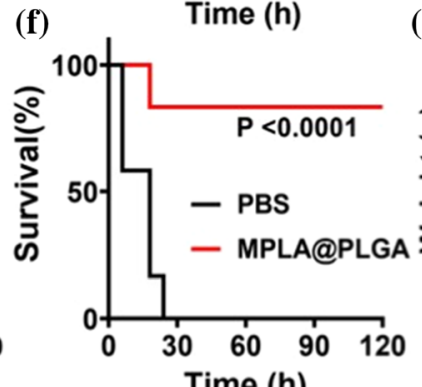

Time (h)
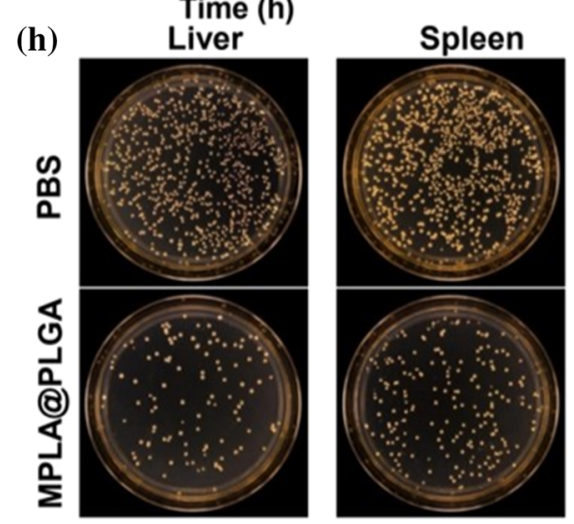

Liver
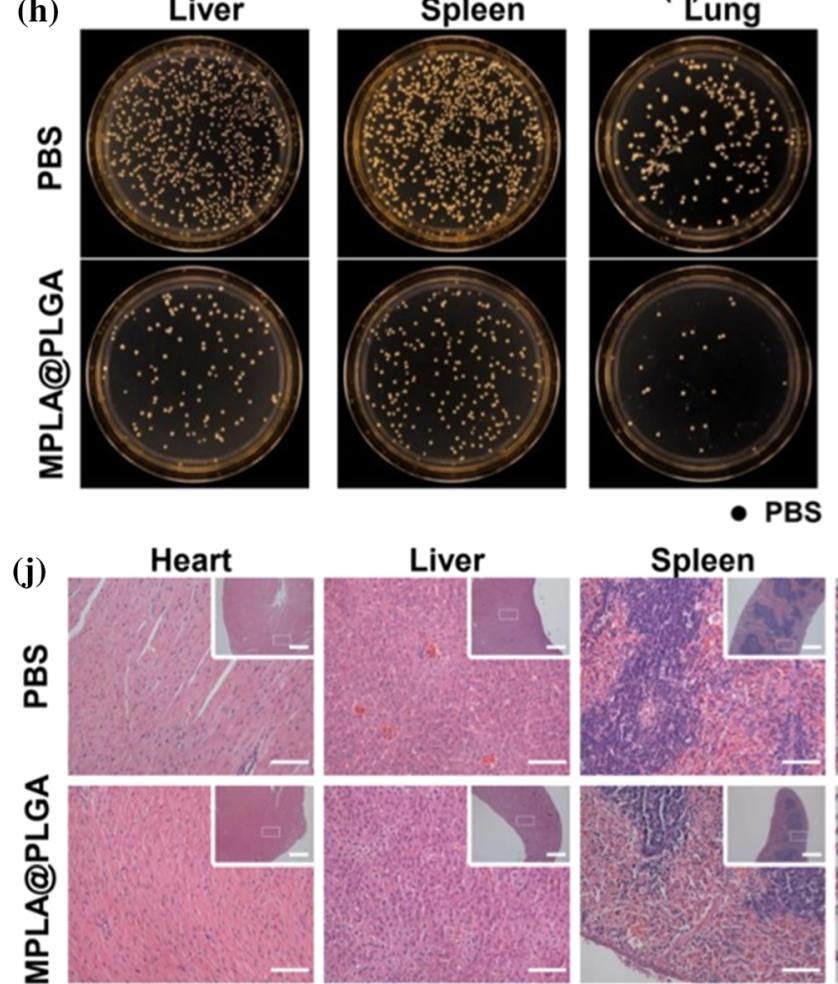

$\underset{\text { time points }}{\stackrel{\text { At different }}{\longrightarrow}}$

E.coli (i.p.) challenge

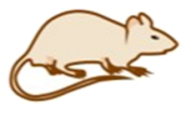

Analysis

(c)
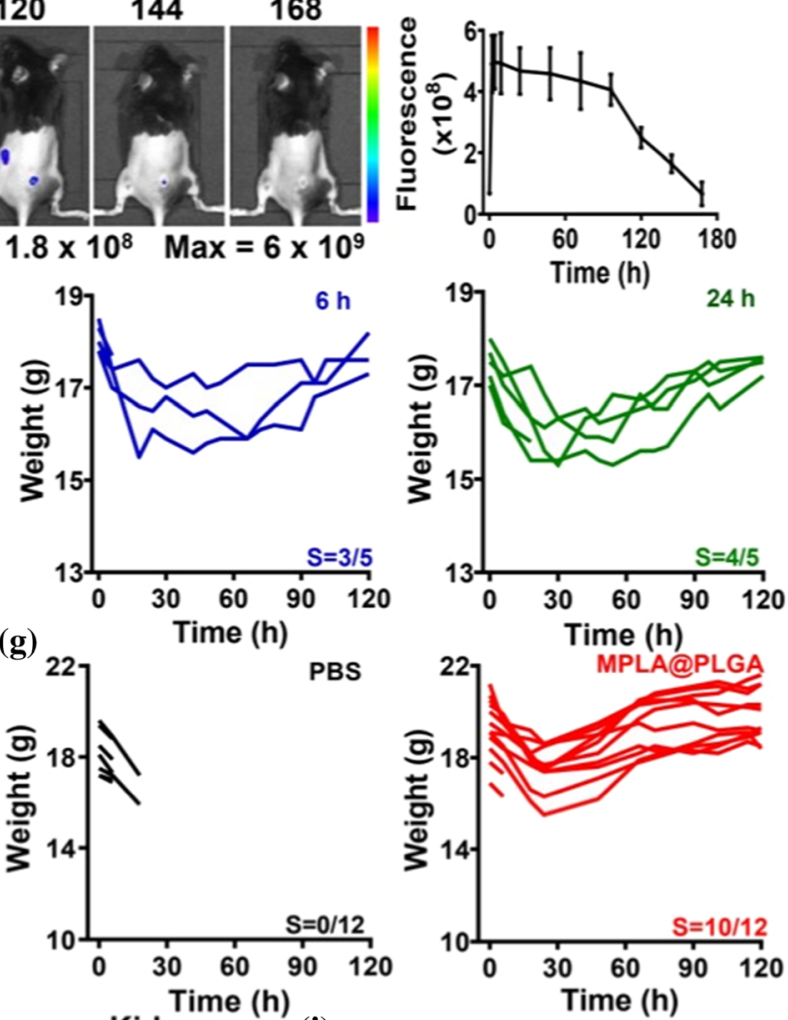

Kidney
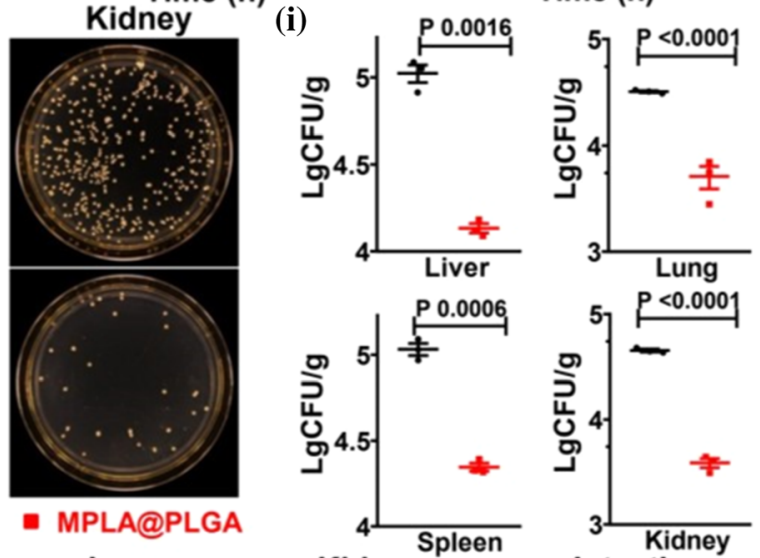

Lung

Kidney Intestine
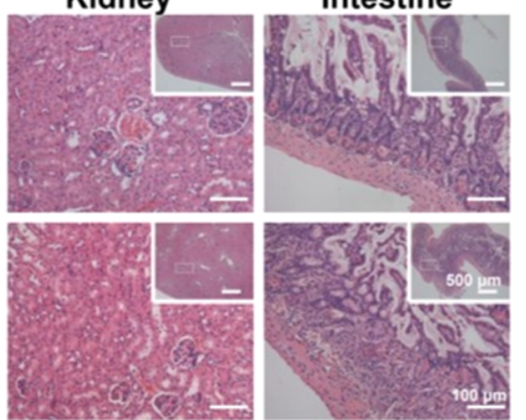
evaluated by the $E$. coli counts in the organs at $6 \mathrm{~h}$ post-lethal infection. It was uncovered that the E. coli counts in MPLA@PLGA group were significantly decreased compared to PBS group (Fig. $2 \mathrm{~h}$ and i), demonstrating enhanced $E$. coli clearance in the MPLA@PLGA-treated mice. Besides, the histology of the major organs in the mice was evaluated by hematoxylin and eosin (H\&E) staining at $16 \mathrm{~h}$ postsepsis challenge. As shown in Fig. $2 \mathrm{j}$, the degree of major organ inflammation and damage in MPLA@PLGA-treated mice was lower than PBStreated mice. All the above results showed that MPLA@PLGA nanoparticles could offer effective sepsis protection.

Thereafter, the in vivo mechanisms of MPLA@PLGA nanoparticles in the protection of E. coli-induced sepsis were studied in detail (Fig. 3a). Firstly, various immune cells in vivo, including natural killer (NK) cells, monocytes, neutrophils and $\mathrm{T}$ cells in blood, were analyzed $24 \mathrm{~h}$ post-intradermal injection. As shown in Figs. $3 b-d$ and S1A-S1E, the percentages of $\mathrm{NK}$ cells, monocytes and $\mathrm{CD} 80^{+} \mathrm{F} 4$ / $80^{+}$cells in MPLA@PLGA group were increased, while the percent of $\mathrm{CD}^{+} \mathrm{T}$ cells, B cells, $\mathrm{CD} 4^{+} \mathrm{T}$ cells, CD206 ${ }^{+} \mathrm{F} 4 / 80^{+}$cells and neutrophils was little changed. Furthermore, the concentrations of different cytokines, measured by enzyme linked immunosorbent assay (ELISA), were not significantly changed between the mice treated with PBS or MPLA@PLGA nanoparticles before sepsis challenge (Figs. $3 \mathrm{i}-\mathrm{n}$ and S2A-S2D), implying the safety of MPLA@PLGA nanoparticles. However, the immune defense in the MPLA@PLGA-treated mice challenged by sepsis was enhanced by up-regulating the percentages of functional immune cells in blood and in abdominal cavity (Figs. 3e-h and S3A-S3E). As exhibited in Figs. 3E3H\&S3A-S3E, the percentages of NK cells, neutrophils and $\mathrm{CD} 80^{+} \mathrm{F} 4 / 80^{+}$cells in the MPLA@PLGA-treated mice were obviously increased after bacterial sepsis challenge, while the percentages of $\mathrm{CD}^{+} \mathrm{T}$ cells, B cells, $\mathrm{CD} 4^{+} \mathrm{T}$ cells, monocytes and $\mathrm{CD} 206^{+} \mathrm{F} 4 / 80^{+}$cells were not significantly changed in the two groups. When the mice were challenged by bacterial infection, the functional cytokines were more secreted in MPLA@PLGA group compared to $\mathrm{PBS}$ group, implying stronger immune response (Figs. $3 \mathrm{i}-\mathrm{n}$ and S2A-2D). These results demonstrated that the in vivo immune response could be effectively enhanced by MPLA@PLGA nanoparticles for sepsis protection.
Given the role of NK cells, neutrophils and $\mathrm{CD} 80^{+} \mathrm{F} 4 / 80^{+}$cells in the above sepsis protection, we chose RAW 264.7 cells, a kind of $\mathrm{F} 4 / 80^{+}$cell line, to mimic and study the in vitro function of MPLA@PLGA nanoparticles. The RAW 264.7 cells were stimulated with PBS or MPLA@PLGA nanoparticles for $6 \mathrm{~h}$. After stimulation, these stimulated cells were cultivated with Cy5.5-labeled and heat-killed E. coli (E. coli-cy5.5) for $30 \mathrm{~min}$. Thereafter, the polarization of RAW 264.7 cells was evaluated by flow cytometry. It was found that MPLA@PLGA nanoparticles could promote the expression of CD80 and M1 polarization of RAW 264.7 cells (Figure S4A$\mathrm{S} 4 \mathrm{C})$. Then, the E. coli uptake was evaluated by E. coli-cy5.5. As exhibited in Figure S5A-S5C, the MPLA@PLGA-treated cells could uptake more E. coli compared to the PBS-treated cells, implying that MPLA@PLGA nanoparticles could enhance bacterial endocytosis of RAW 264.7 cells. Furthermore, the cells treated by MPLA@PLGA nanoparticles could more effectively kill bacteria than that treated by PBS (Figure S6A\&S6B), demonstrating that MPLA@PLGA nanoparticles could enhance the bactericidal capacity of RAW 264.7 cells. The above results showed that the bactericidal ability of RAW 264.7 cells treated by MPLA@PLGA nanoparticles was enhanced by promoting M1 polarization and increasing bacterial uptake.

The clinical researches showed that more than half of the patients with sepsis would encounter with a period of continuous immunosuppression, in which the patients would easier suffer from secondary infection within a few weeks or months compared to healthy human. Therefore, the immune system in the lived mice was analyzed at 30 days after sepsis challenge (Fig. 4a). It was found that the percentages of $\mathrm{CD}^{+}{ }^{+} \mathrm{T}$ cells, NK cells, monocytes, $\mathrm{B}$ cells and memory $\mathrm{CD}^{+} \mathrm{T}$ cells were obviously decreased (Figs. $4 \mathrm{~b}-\mathrm{f}$ and S7A-S7E), implying the destruction of immunity homeostasis in the MPLA@PLGA-treated mice lived from sepsis challenge. However, the percentages of neutrophils, $\mathrm{CD} 8^{+} \mathrm{T}$ cells and memory $\mathrm{CD}^{+} \mathrm{T}$ cells in the survived mice were significantly increased, implying the generation of immune memory and enhanced antibacterial capability (Figs. 4g-i and S8A-S8C). Moreover, the secretion of various functional cytokines, particularly including IL-1 $\beta$, IL-27, IL-17A, IFN- $\beta$ and IL-10, was significantly increased in the MPLA@PLGA-treated mice lived from the lethal E. coli challenge (Figs. $4 \mathrm{j}-\mathrm{n}$ and 
(a)
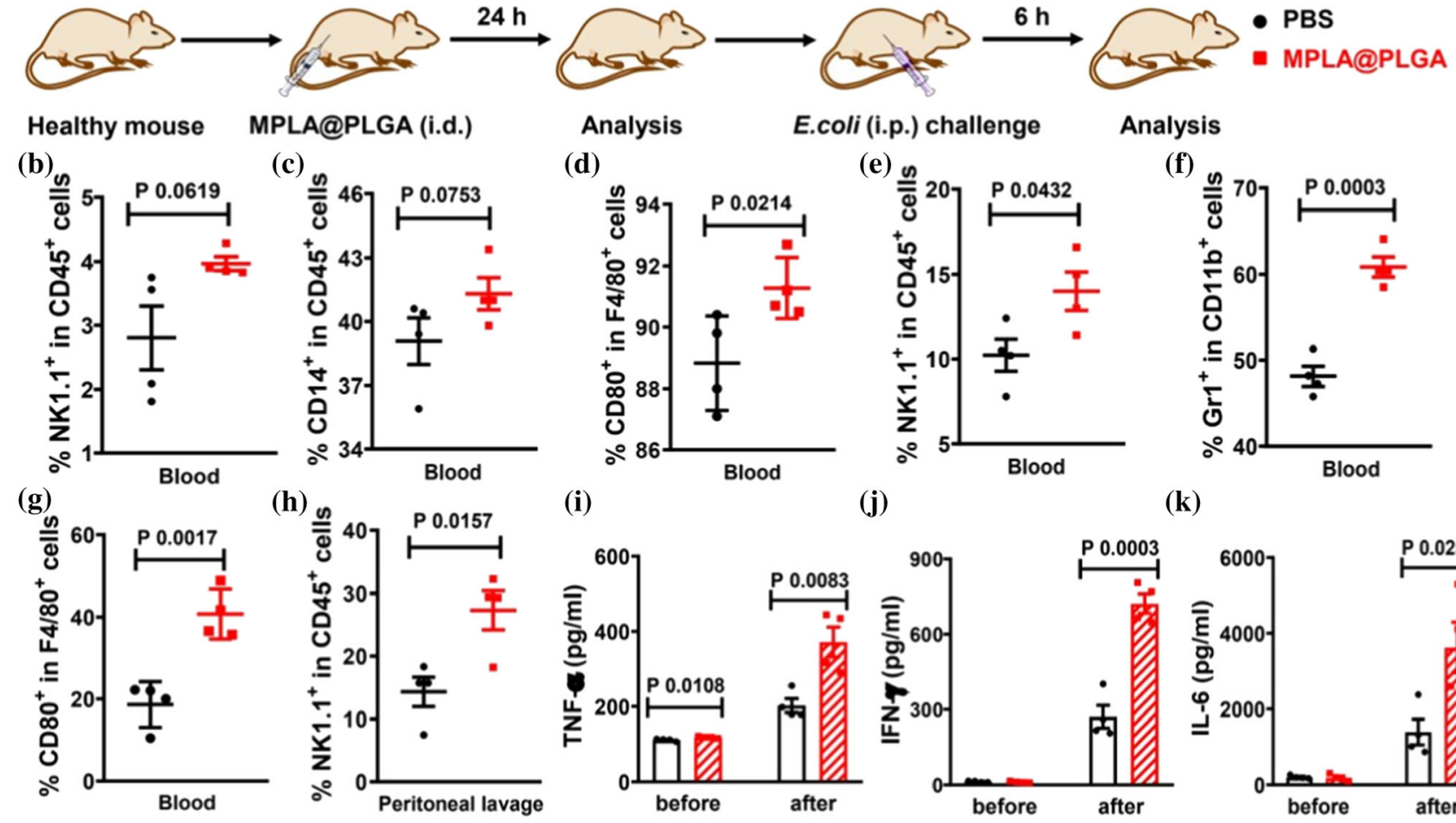

(d)

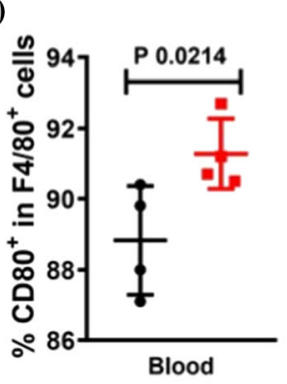

(e)

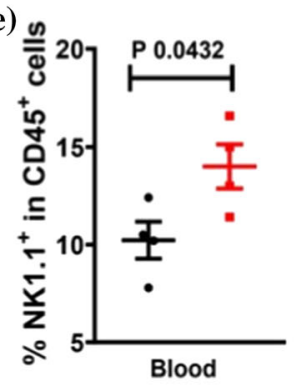

(f)

(i)

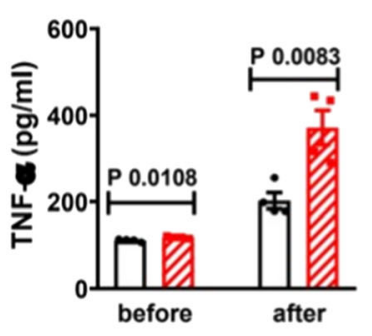

(n) (j)

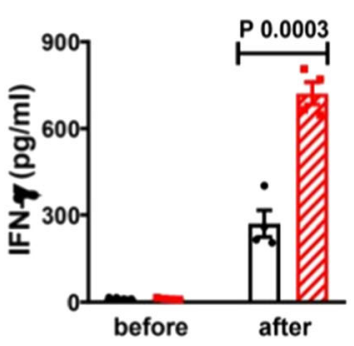

(k)
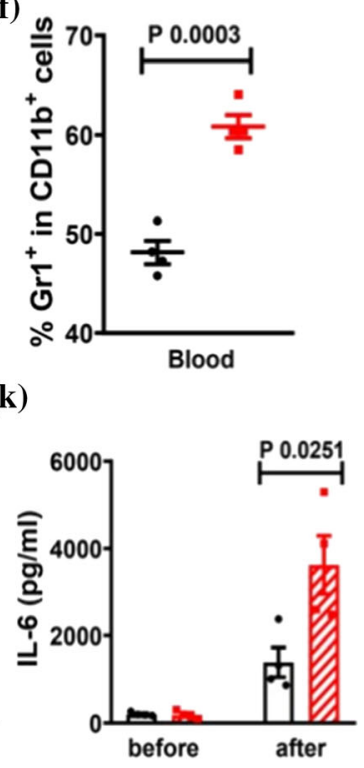

(l)

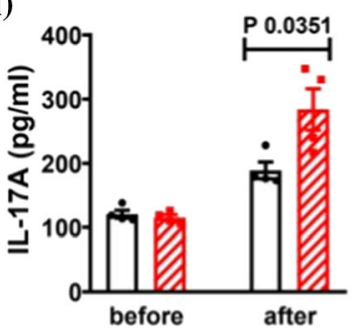

(m)
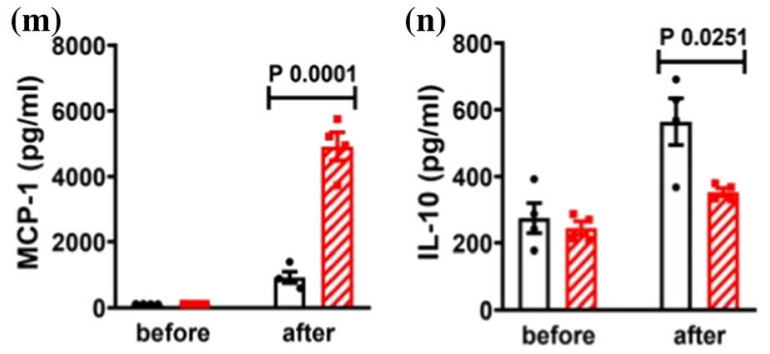

Figure 3 The in vivo changes of immune phenotypes induced by the MPLA@PLGA nanoparticles. a Schematic illustration to evaluate the change of immune phenotypes in the mice with different treatments before or after $E$. coli-induced sepsis challenge. (b-d) The proportions of NK cells $\left(\mathrm{NK} 1.1^{+}\right)$in $\mathrm{CD} 45^{+}$cells (b), monocytes $\left(\mathrm{CD} 14^{+}\right)$in $\mathrm{CD}^{+} 5^{+}$cells (c) and $\mathrm{CD}^{+} 0^{+}$cells in $\mathrm{F} 4 / 80^{+}$cells $(\mathbf{d})$ in blood of the mice pretreated with the MPLA@PLGA nanoparticles before sepsis challenge. (eh) The proportions of $\mathrm{NK}$ cells $\left(\mathrm{NK} 1.1^{+}\right)$in $\mathrm{CD}_{4} 5^{+}$cells $(\mathbf{e})$,

S9A-S9E), showing the enhanced capacity for secondary E. coli-induced sepsis protection. Furthermore, the E. coli counts in the organs of the mice, including liver, spleen, lung and kidney, further confirmed the improved capacity to resist E. coli infection in the survived mice (Fig. 4o and p).

To evaluate the capacity of MPLA@PLGA-treated mice survived from lethal $E$. coli infection to resist secondary infection, the survived mice and the healthy mice were challenged by various lethal infections neutrophils $\left(\mathrm{Gr}-1^{+}\right)$in $\mathrm{CD}_{11 b^{+}}$cells $(\mathbf{f}), \mathrm{CD} 80^{+}$cells in $\mathrm{F} 4 / 80^{+}$ cells $(\mathbf{g})$ in blood and NK cells $\left(\mathrm{NK} 1.1^{+}\right)$in $\mathrm{CD}^{+} 5^{+}$cells $(\mathbf{h})$ in peritoneal lavage of the mice from the two groups after sepsis challenge ( $\mathrm{n}=4$ per group). (i-n) Cytokine levels including TNF$\alpha(\mathbf{i}), \operatorname{IFN}-\gamma(\mathbf{j}), \operatorname{IL}-6(\mathbf{k}), \operatorname{IL}-17 \mathrm{~A}(\mathbf{1}), \operatorname{MCP}-1$ (m) and IL-10 (n) in sera from the pretreated mice before or at $6 \mathrm{~h}$ after $E$. coli challenge ( $n=4$ per group). Data are presented as means \pm SEM. Statistical significance was calculated by Student's t-test.

(Fig. 5a). It was amazing that all the MPLA@PLGAtreated mice lived from the first lethal E. coli infection, even though in the state of immunity disorder, could resist the second sepsis challenge (E. coli $1 \times 10^{7} \mathrm{CFU}, 200 \mu \mathrm{L}$ ) (Fig. 5b). The body weight of the mice lived from sepsis challenge could be back to the initial weight about 4 days after the second E. coliinduced sepsis (Fig. 5c). However, the MPLA@PLGA-treated mice lived from the first E. coli infection could not resist lethal S.a.u infection 
(a)

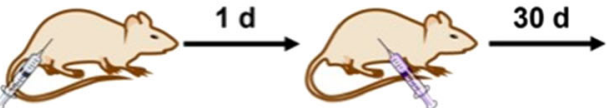

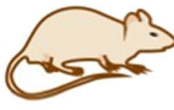

Analysis

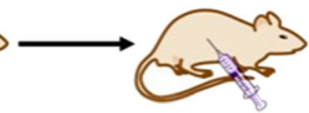

E.coli (i.p.) challenge

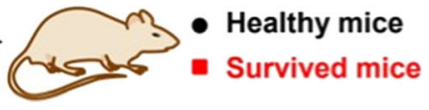

Analysis (b)
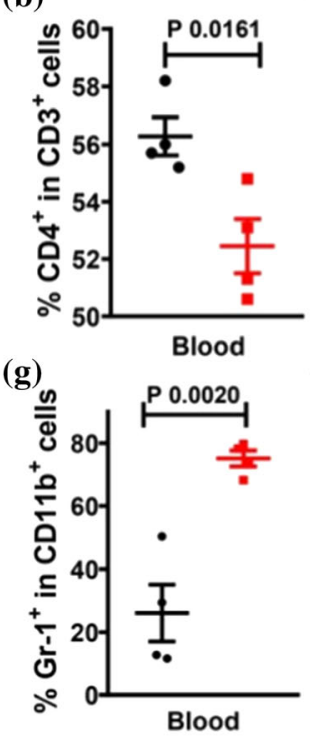

(l)

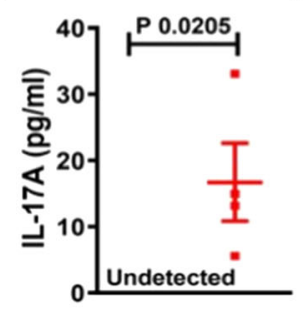

(p)

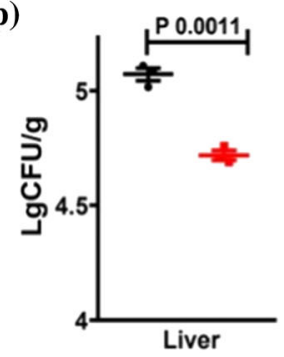

(c)

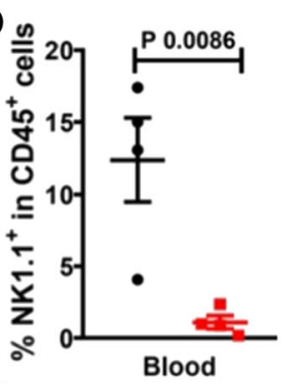

(h)

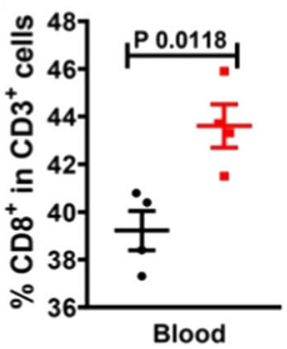

(m)
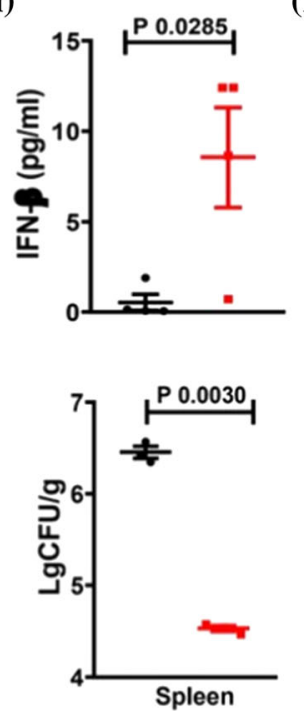

(d)

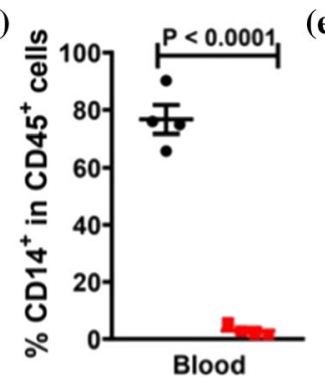

(i)

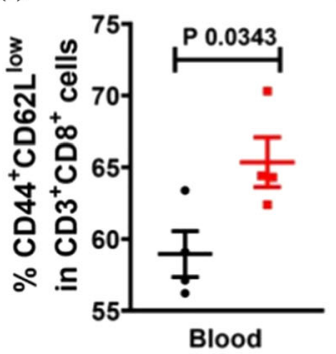

(n)

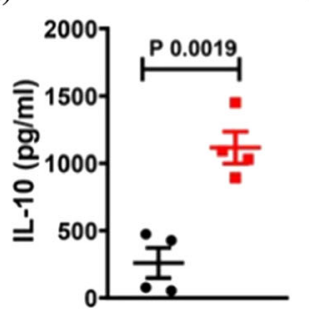

(f)

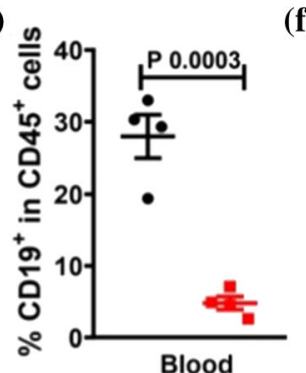

(j)

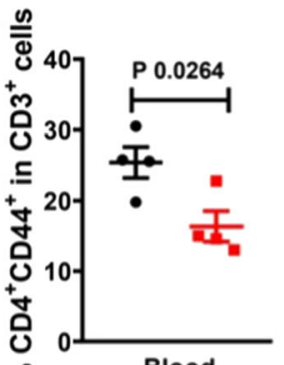

(k) ${ }^{\circ}$
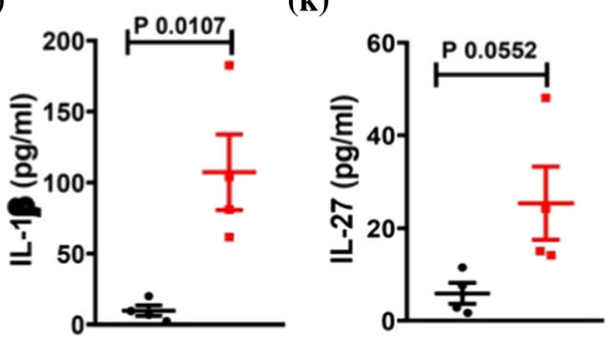

(o) Liver Spleen Lung Kidney
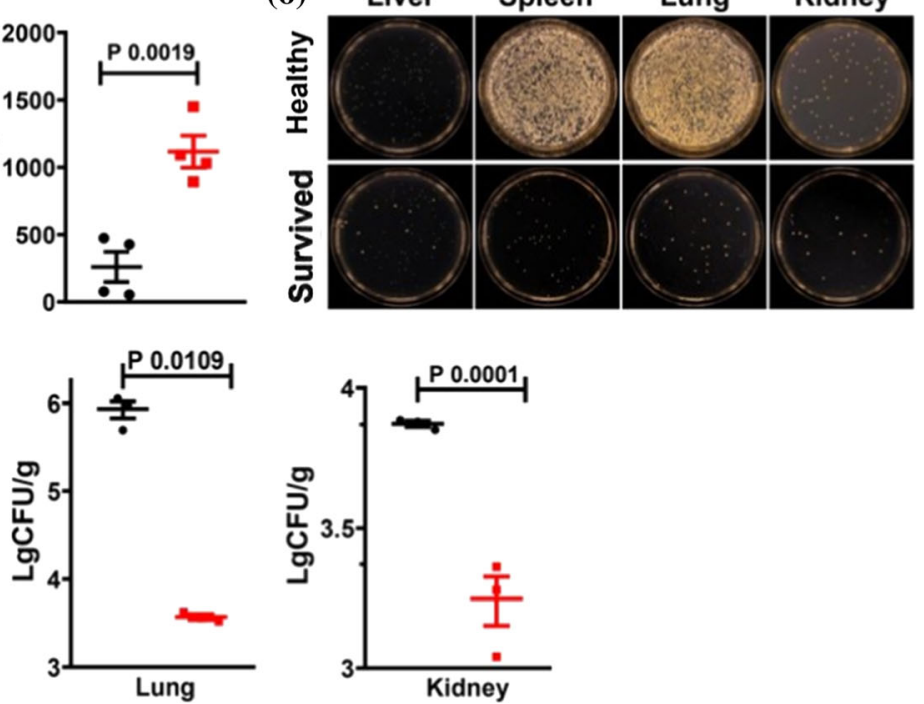

Figure 4 In vivo protection for $E$. coli-induced sepsis again in survival mice. a Schematic illustration to evaluate the changes of immune cells for repeated $E$. coli-induced sepsis in the survival mice. (b-i) The percent of $\mathrm{CD}^{+}{ }^{+} \mathrm{T}$ cells in $\mathrm{CD} 3^{+} \mathrm{T}$ cells $(\mathbf{b}), \mathrm{NK}$ cells $\left(\mathrm{NK} 1.1^{+}\right)$in $\mathrm{CD}_{4} 5^{+}$cells (c), monocytes $\left(\mathrm{CD} 14^{+}\right)$in $\mathrm{CD} 45^{+}$ cells $(\mathbf{d}), \mathrm{B}$ cells $\left(\mathrm{CD} 19^{+}\right)$in $\mathrm{CD} 5^{+}$cells $(\mathbf{e}), \mathrm{CD}^{+} \mathrm{T}_{\mathrm{m}}$ cells $\left(\mathrm{CD}^{+} \mathrm{CD}^{+} 4^{+}\right)$in $\mathrm{CD}^{+}$cells $(\mathbf{f})$, neutrophils $\left(\mathrm{Gr}-1^{+}\right)$in $\mathrm{CD} 11 \mathrm{~b}^{+}$ cells $(\mathrm{g}), \mathrm{CD}^{+} \mathrm{T}^{-}$cells in $\mathrm{CD}^{+} \mathrm{T}$ cells $(\mathbf{h})$ and $\mathrm{CD} 8^{+} \mathrm{T}_{\mathrm{em}}$ cells $\left(\mathrm{CD} 44^{+} \mathrm{CD} 62 \mathrm{~L}^{\text {low }}\right)$ in $\mathrm{CD}^{+} \mathrm{CD}^{+}$cells (I) in the blood of normal healthy mice and the mice survived at 30 days after the first sepsis challenge ( $n=4$ per group). $\mathbf{j}-\mathbf{n}$ Cytokine levels including IL-1 $\beta$ (j), IL-27 (k), IL-17A (1), IFN- $\beta$ (M) and IL-10 (n) in sera from the normal mice or the survived mice at 30 days after the first sepsis challenge ( $n=4$ per group). $\mathbf{o}$ and $\mathbf{p}$ Representative images (o) and the statistic data (p) of E. coli colonization in the major organs of the mice at $6 \mathrm{~h}$ after the second sepsis challenge $(n=3$ per group). Data are presented as means \pm SEM. Statistical significance was calculated by Student's t-test. 
(a)

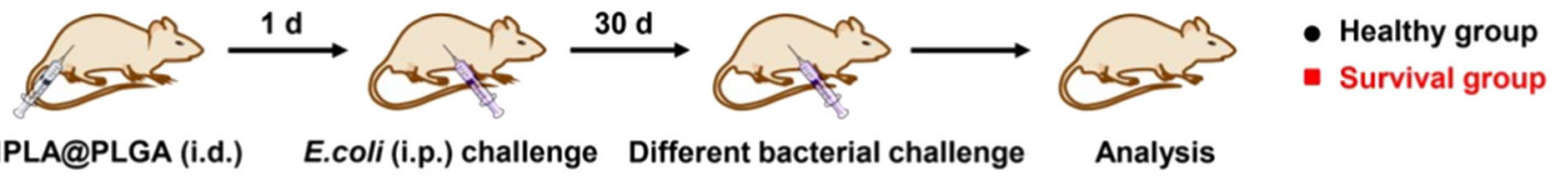

(b)

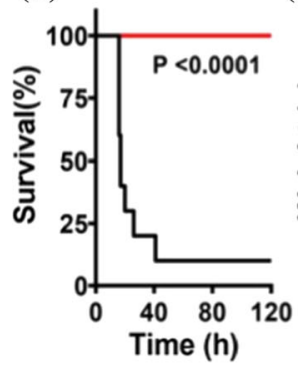

(c)

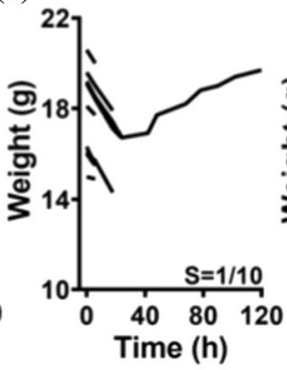

(d)

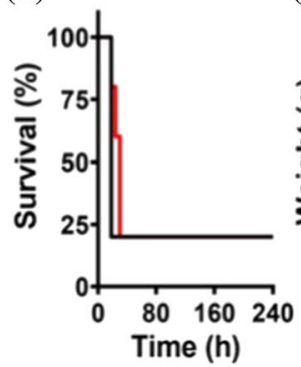

(e)

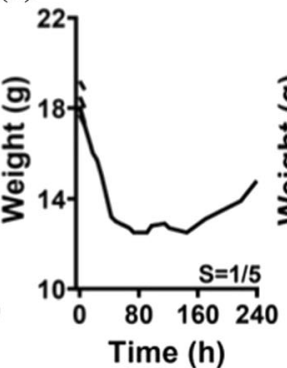

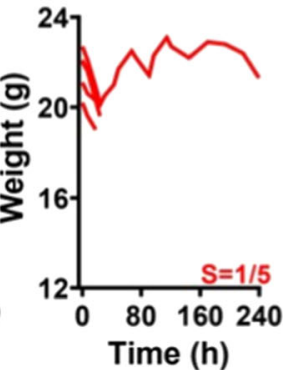

Figure 5 In vivo protection for repeated E. coli-induced sepsis in the survived mice. a Schematic illustration to show the protection effect against for repeated sepsis in the survival mice. $\mathbf{b}$ and c Survival rate (b) and individual body weight (c) of the mice after repeated $E$. coli-induced sepsis challenge ( $n=10$ per group).

$\left(1.4 \times 10^{8} \mathrm{CFU}, 200 \mu \mathrm{L}\right)$ to achieve S.a.u-induced sepsis protection (Fig. $5 \mathrm{~d}$ and e). Therefore, the MPLA@PLGA nanoparticles as a kind of nano-drug could effectively and specifically protect the mice from repeated E. coli-induced sepsis.

\section{Conclusion}

In this study, a kind of nano-drug (MPLA@PLGA nanoparticles) was developed by encapsulating MPLA, a hydrophobic TLR4 agonist, with PLGA nanoparticles for sepsis protection. Such nanoparticles could activate in vivo innate immune system by up-regulating the percentages of NK cells and macrophages in the blood and the lesion, increasing the levels of various functional cytokines and accelerating E. coli clearance in major organs to achieve sepsis protection after E. coli-induced sepsis challenge. Furthermore, the mice pre-treated with the MPLA@PLGA nanoparticles that survived after first sepsis challenge could resist the second sepsis challenge by building acquired immunity for $E$. coli infection. Therefore, this nanoparticle could be served as a simple but effective nano-drug in the prevention and protection of E. coli-induced sepsis.

d and e Survival rate (d) and individual body weight (e) of the mice after S.a.u.-induced sepsis challenge ( $n=5$ per group). S, survival rate. Data are presented as means \pm SEM. Statistical significance was calculated by log-rank test.

\section{Acknowledgements}

This work was supported by the National Natural Science Foundation of China (81671967, 81871594, 52003183), Suzhou Science and Technology Project (SS2019011, BE2020659, SYS2018067, SYS2020150), Suzhou Clinical Medicine Center (Szzxj201505), Jiangsu Province's Key Subject (FXK201731), the Natural Science Foundation of Jiangsu Province (BK20190053, BK20190186, 21KJB320010), Natural Science Foundation of Inner Mongolia Autonomous Region (2021MS08041), the Medical Science Program of Jiangsu Province (H2019002), Postgraduate Research \& Practice Innovation Program of Jiangsu Province (KYCX21_2981), Suzhou Clinical Medicine Expert Project (SZYJTD201706) and Jiangsu Provincial Medical Talent (JCRCB2016001).

\section{Declarations}

Conflict of interest The authors declare no competing financial interest.

Supplementary Information: The online version contains supplementary material available at http s://doi.org/10.1007/s10853-021-06638-y.

Open Access This article is licensed under a Creative Commons Attribution 4.0 International License, which permits use, sharing, adaptation, distribution and reproduction in any medium or format, as long 
as you give appropriate credit to the original author(s) and the source, provide a link to the Creative Commons licence, and indicate if changes were made. The images or other third party material in this article are included in the article's Creative Commons licence, unless indicated otherwise in a credit line to the material. If material is not included in the article's Creative Commons licence and your intended use is not permitted by statutory regulation or exceeds the permitted use, you will need to obtain permission directly from the copyright holder. To view a copy of this licence, visit http://creativecommons.org/licen ses/by/4.0/.

\section{References}

[1] Park J, Kim H, Kwon KW, Choi HH, Kang SM, Hong JJ, Shin SJ (2020) Toll-like receptor 4 signaling-mediated responses are critically engaged in optimal host protection against highly virulent Mycobacterium tuberculosis $\mathrm{K}$ infection. Virulence 11:430-445. https://doi.org/10.1080/21 505594.2020.1766401

[2] Ziv-On E, Friger MD, Saidel-Odes L, Borer A, Shimoni O, Nikonov A, Nesher L (2021) Impact of an antibiotic stewardship program on the incidence of resistant Escherichia coli: a quasi-experimental study. Antibiot Basel 10:179. h ttps://doi.org/10.3390/antibiotics10020179

[3] Singer M, Deutschman CS, Seymour CW, Shankar-Hari M, Annane D, Bauer M, Bellomo R, Bernard GR, Chiche JD, Coopersmith CM (2016) The third international consensus definitions for sepsis and septic shock. JAMA 315(8):801-810. https://doi.org/10.1001/jama.2016.0287

[4] Rhee C, Dantes R, Epstein L, Murphy DJ, Seymour CW, Iwashyna TJ, Kadri SS, Angus DC, Danner RL, Fiore AE (2017) Incidence and trends of sepsis in US hospitals using clinical vs claims data, 2009-2014. JAMA 318:1241-1249. https://doi.org/10.1001/jama.2017.13836

[5] Raith EP, Udy AA, Bailey M, McGloughlin S, MacIsaac C, Bellomo R, Pilcher DV (2017) Australian and New Zealand intensive care society (ANZICS) centre for outcomes and resource evaluation (CORE). Prognostic accuracy of the SOFA score, SIRS criteria, and qSOFA score for in-hospital mortality among adults with suspected infection admitted to the intensive care unit. JAMA 317:290-300. https://doi.org/ 10.1001/jama.2016.20328

[6] Seidel G, Gaser C, Götz T, Günther A, Hamzei F (2020) Accelerated brain ageing in sepsis survivors with cognitive long-term impairment. Eur J Neurosci 52(10):4395-4402. h ttps://doi.org/10.1111/ejn.14850
[7] Caraballo C, Jaimes F (2019) Organ dysfunction in sepsis: an ominous trajectory from infection to death. Yale J Biol Med 92(4):629-640

[8] Chung HY, Wickel J, Brunkhorst FM, Geis C (2020) Sepsisassociated encephalopathy: from delirium to dementia? J Clin Med 9(3):703. https://doi.org/10.3390/jcm9030703

[9] Rossi G, Tucci A, Cariani E, Ravaggi A, Rossini A, Radaeli E (1997) Outbreak of hepatitis C virus infection in patients with hematologic disorders treated with intravenous immunoglobulins: different prognosis according to the immune status. Blood 90:1309-1314

[10] Jian W, Gu L, Williams B, Feng Y, Chao W, Zou L (2019) Toll-like receptor 7 contributes to inflammation, organ injury, and mortality in murine sepsis. Anesthesiology 131:105-118. https://doi.org/10.1097/ALN. 0000000000002706

[11] Phares TW, Kotraiah V, Chung CS, Unsinger J, Mazer M, Remy KE, Browne CD, Buontempo P, Mansour M, Pannucci J (2021) A Peptide-Based checkpoint immunomodulator alleviates immune dysfunction in murine polymicrobial sepsis. Shock 55(6):806-815. https://doi.org/10.1097/SHK. 0000000000001682

[12] Zeng W, Jin L, Zhang F, Zhang C, Liang W (2018) Naringenin as a potential immunomodulator in therapeutics. Pharmacol Res 135:122-126. https://doi.org/10.1016/j.phrs. 2018.08.002

[13] Yang H, Wang H, Ju Z, Ragab AA, Lundbäck P, Long W, Valdes-Ferrer SI, He M, Pribis JP, Li J (2015) MD-2 is required for disulfide HMGB1-dependent TLR4 signaling. J Exp Med 212:5-14. https://doi.org/10.1084/jem.20141318

[14] Emlet DR, Shaw AD, Kellum JA (2020) Sepsis-associated AKI: epithelial cell dysfunction. Semin Nephrol 35:85-95. h ttps://doi.org/10.1016/j.semnephrol.2015.01.009

[15] Hatinguais R, Willment JA, Brown GD (2020) PAMPs of the fungal cell wall and mammalian PRRs. Curr Top Microbiol Immunol 425:187-223. https://doi.org/10.1007/82_2020_ 201

[16] Zhuang C, Liu G, Barkema HW, Zhou M, Xu S, Ur Rahman S, Liu Y, Kastelic JP, Gao J, Han B (2020) Selenomethionine suppressed TLR4/NF- $\mathrm{KB}$ pathway by activating selenoprotein $\mathrm{S}$ to alleviate ESBL Escherichia coli-induced inflammation in bovine mammary epithelial cells and macrophages. Front Microbiol 11:1461. https://doi.org/10.3 389/fmicb.2020.01461

[17] de Souza Pires-Neto O, Amoras EDSG, Queiroz M, Demachki S, da Silva Conde SR, Ishak R, Cayres-Vallinoto I, Vallinoto A (2020) Hepatic TLR4, MBL and CRP gene expression levels are associated with chronic hepatitis C. Infect Genet Evol 80:104200. https://doi.org/10.1016/j.meeg id.2020.104200 
[18] Yan C, Wu J, Xu N, Li J, Zhou QY, Yang HM, Cheng XD, Liu JX, Dong X, Koda S (2021) TLR4 deficiency exacerbates biliary injuries and peribiliary fibrosis caused by Clonorchis sinensis in a resistant mouse strain. Front Cell Infect Microbiol 10:526997. https://doi.org/10.3389/fcimb.2020. 526997

[19] Swanson L, Katkar GD, Tam J, Pranadinata RF, Chareddy Y, Coates J, Anandachar MS, Castillo V, Olson J, Nizet V (2020) TLR4 signaling and macrophage inflammatory responses are dampened by GIV/Girdin. Proc Natl Acad Sci USA 117:26895-26906. https://doi.org/10.1073/pnas. 2011667117

[20] Kim M, Lee JE, Cho H, Jung HG, Lee W, Seo HY, Lee SH, Ahn DG, Kim SJ, Yu JW (2020) Antiviral efficacy of orally delivered neoagarohexaose, a nonconventional TLR4 agonist, against norovirus infection in mice. Biomaterials 263:120391. https://doi.org/10.1016/j.biomaterials.2020. 120391

[21] Hernandez A, Patil NK, Stothers CL, Luan L, McBride MA, Owen AM, Burelbach KR, Williams DL, Sherwood ER, Bohannon JK (2019) Immunobiology and application of tolllike receptor 4 agonists to augment host resistance to infection. Pharmacol Res 150:104502. https://doi.org/10.10 16/j.phrs.2019.104502

[22] Ruchaud-Sparagano MH, Mills R, Scott J, Simpson AJ (2014) MPLA inhibits release of cytotoxic mediators from human neutrophils while preserving efficient bacterial killing. Immunol Cell Biol 92:799-809. https://doi.org/10.1038/ icb. 2014.55

[23] Albert Vega C, Karakike E, Bartolo F, Mouton W, Cerrato E, Brengel-Pesce K, Giamarellos-Bourboulis EJ, Mallet F,
Trouillet-Assant S (2021) Differential response induced by LPS and MPLA in immunocompetent and septic individuals. Clin Immunol 226:108714. https://doi.org/10.1016/j.clim.2 021.108714

[24] Yang Z, Wang L, Yu H, Wang R, Gou Y, Zhang M, Kang C, Liu T, Lan Y, Wang X (2019) Membrane TLR9 positive neutrophil mediated MPLA protects against fatal bacterial sepsis. Theranostics 9:6269-6283. https://doi.org/10.7150/th no.37139

[25] Khademi F, Yousefi A, Derakhshan M, Najafi A, Tafaghodi M (2020) Enhancing immunogenicity of novel multistage subunit vaccine of Mycobacterium tuberculosis using PLGA:DDA hybrid nanoparticles and MPLA: subcutaneous administration. Iran J Basic Med Sci 22:893-900. https://doi. org/10.22038/ijbms.2019.33962.8079

[26] Mir M, Ahmed N, Rehman AU (2017) Recent applications of PLGA based nanostructures in drug delivery. Colloids Surf B Biointerfaces 159:217-231. https://doi.org/10.1016/ j.colsurfb.2017.07.038

[27] Han X, Wang R, Xu J, Chen Q, Liang C, Chen J, Zhao J, Chu J, Fan Q, Archibong E (2019) In situ thermal ablation of tumors in combination with nano-adjuvant and immune checkpoint blockade to inhibit cancer metastasis and recurrence. Biomaterials 224:119490. https://doi.org/10.1016/j.b iomaterials.2019.119490

Publisher's Note Springer Nature remains neutral with regard to jurisdictional claims in published maps and institutional affiliations. 